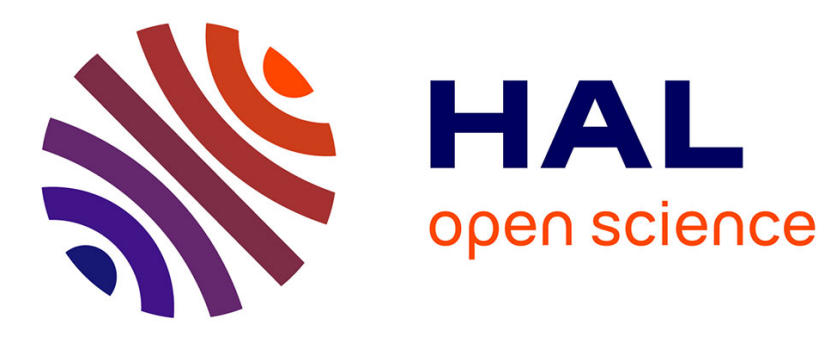

\title{
Sulcal variability in a computerized brain atlas
}

\author{
Michel Desvignes, Nicolas Royackkers, Marinette Revenu
}

\section{To cite this version:}

Michel Desvignes, Nicolas Royackkers, Marinette Revenu. Sulcal variability in a computerized brain atlas. IEEE EMBS 96, 1996, Amsterdam, Netherlands. pp.700-701, 10.1109/IEMBS.1996.651935 . hal-00975253

\section{HAL Id: hal-00975253 \\ https://hal.science/hal-00975253}

Submitted on 8 Apr 2014

HAL is a multi-disciplinary open access archive for the deposit and dissemination of scientific research documents, whether they are published or not. The documents may come from teaching and research institutions in France or abroad, or from public or private research centers.
L'archive ouverte pluridisciplinaire HAL, est destinée au dépôt et à la diffusion de documents scientifiques de niveau recherche, publiés ou non, émanant des établissements d'enseignement et de recherche français ou étrangers, des laboratoires publics ou privés. 


\title{
SULCAL VARIABILITY IN A COMPUTERIZED BRAIN ATLAS
}

\author{
Michel Desvignes, Nicolas Royackkers, Marinette Revenu \\ GREYC-ISMRA-Université de Caen (URA CNRS 1526) \\ 6, Bd Maréchal Juin 14050 CAEN Cedex FRANCE \\ Email : (Michel.Desvignes, Nicolas.Royackkers)@greyc.ismra.fr, \\ Tel : (33) 31452701 , Fax : (33) 31452698
}

\begin{abstract}
Computerized sulci atlas includes a mean representation of a standard brain in a standardized coordinate space, such as the Talairach's grid. In this reference system, differences between sulci at the surface of the brain are due to shape differences of the brain and to intrinsic anatomical differences of sulci. In this paper, four different methods are compared: non-proportional, global linear, local linear (Talairach) and non linear methods. From nine brains where sulci are labeled, a model of their mean location and its variability is computed. As expected, non linear method is the most accurate one, with fewer variations than others.
\end{abstract}

\section{INTRODUCTION}

Standard brain atlases [1-3] are useful tools for neurosurgical planning, interpretation of functional examinations (PET, fMRI, MEG), neuro-radiology, and several works deal with sulci atlases [4-6]. When computerized brain atlases are to be build, they must include the best standard representation of the brain as well as information about the variations of its shape [7]. Two classes of variability can be distinguished : the first one is predictable and relative to the variation of the size of the brain and to the shape of the surface of the brain. The second one is un-predictable and relative to the anatomical inter-individual differences of sulci. Standard Talairach space [8] deals with size of brain [9], but not with local shape.

Four methods for building an atlas of the human cortical sulci from 3D MRI are compared. They reduce the first class variability and build a model of the second class variability. Sulci are represented as 3D curves drawn onto the external surface of the brain. The atlas will then be used for the automatic recognition of main sulci in MR examinations.

\section{MATERIALS}

3D MRI are obtained from the hospital of CAEN, from a General Electric SIGNA 1,5 T system, with SPGR 3D sequence ( $\mathrm{T} 1$ weighted, $\mathrm{Te}=8 \mathrm{~ms}, \mathrm{TR}=40 \mathrm{~ms}$, flip $=45^{\circ}$ ). Volumes are stored as $256 \times 256 \times 124$ isotropic voxels $(1,3$ or $1,5 \mathrm{~mm}^{3}$ ). 35 healthy volunteers ( 13 females, 22 males, 22-54 years old) were examinated to get measurements on brain, and nine of them for measurements on sulci.

\section{METHODS}

Six sulci (lateral, central, pre-central, post-central, superior temporal, superior frontal) have been identified on each hemisphere of 9 MRI brain by an automatic procedure [10], which draws 3D curves onto the surface of the brain. These curves have been validated by 3 medical experts. These 9 examinations compose our training set.

For each curve, the following features are extracted: principal direction, center of gravity, length, depth, relations between curves (distances and vectors between centers of gravity).

From the 9 curves which represent the same sulcus on different brains, a mean (resp. variability) model of localization is built: a mean curve (resp. search area). Mean curve is the mean position of the 9 parametrized curves. Search area is obtained from the 9 curves, processed with hole filling and geodesic dilatation to obtain a compact zone.

Since size and shape of the surface brain are very different (see table I), mean curve and search area must be calculated in the same coordinate system for all the brains.

\begin{tabular}{|c|c|c|c|c|c|}
\hline & nean. & 6. & (17nn: & 1110 & (3) \\
\hline (cand $($ Inin) & 172 & 6 & 153 & 182 & $11 \%$ \\
\hline Metril & 120 & 5 & 107 & 133 & $11 \%$ \\
\hline 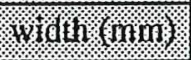 & 137 & 7 & 113 & 146 & $17 \%$ \\
\hline 1engtivinidu & 1,27 & 0,08 & 1,09 & 1,53 & $21 \%$ \\
\hline Herothilieing & 1,44 & 0,07 & 1,26 & 1,58 & $13 \%$ \\
\hline 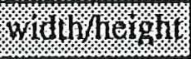 & 1,14 & 0,07 & 0,93 & 1,37 & $20 \%$ \\
\hline (Vonne & 1,39 & 0,12 & 1,15 & 1,58 & $17 \%$ \\
\hline
\end{tabular}

Table I : variations of brain measurements on $35 \mathrm{MRI}$

All brains are first registered in a coordinate system, and then, features are calculated. Four different coordinate systems are tested :

Method 1: registration of the center of gravity of the brain. No scaling is performed.

Method 2: method 1 with scaling factor (length, height, width) along the three axes of the brain.

Method 3: registration in the standard Talairach space.

Method 4: method 3, with a projection of the 9 curves onto the surface of the brain under examination. This 
projection onto the brain surface is done using the nearest neighbor method. Talaraich registration suppresses variability of size of the brain, whereas the projection aims at suppressing the variability of shape. There is no longer one standard brain: each brain becomes the reference when it is examined. The coordinate system is given by the Talairach space of this brain, and the surface of the brain.

\section{RESULTS AND DISCUSSION}

Fig. 1 shows the 9 curves registered with the four methods for the lateral (sylvian fissure) and central (Rolando) sulci.

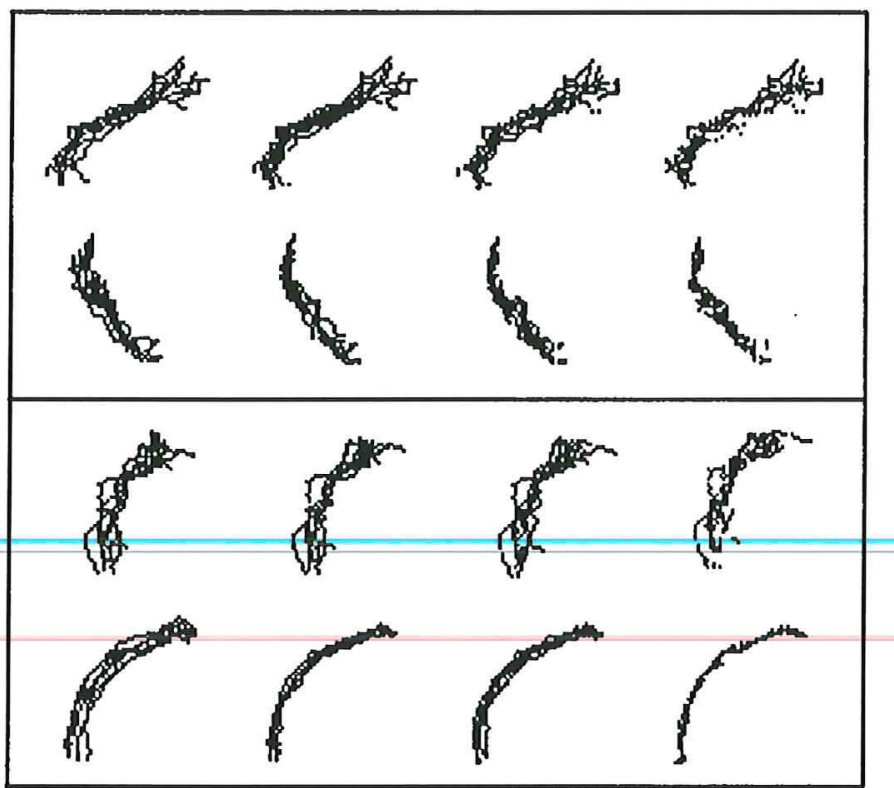

Fig 1: Sagittal and coronal projection of lateral (top) and central (bottom) sulci. From left to right, methods $1,2,3,4$.

From visual observation, we can see that method 2 and method 3 (Talairach) are quite identical. In fact, they are global linear (method 2) or local linear (method 3) methods. As expected, method 4 performs better, and the registrated sulci form a more compact area.

\begin{tabular}{|c|c|c|c|c|}
\hline & II & $110100 \mathrm{C}$ & $11+140 \mathrm{~K}$ & Xneflod \\
\hline 10101.1 & 3.9 & 3.3 & 3.2 & 2.9 \\
\hline cenut & 4.4 & 3.6 & 3.9 & 3.5 \\
\hline 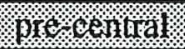 & 4.6 & 3.9 & 4.2 & 3.6 \\
\hline oost cemial & 5.2 & 4.6 & 4.7 & 4.6 \\
\hline Kromoral & 5.0 & 4.1 & 3.9 & 3.6 \\
\hline $814011 \%$ & 5.1 & 4.7 & 5.0 & 4.4 \\
\hline
\end{tabular}

Table II : Mean distance ( $\mathrm{mm}$ ) between sulci and model

Quantitative evaluation is given in table II. The mean distance between the nine curves and the mean curve is computed: this is a measure of the dispersion of the location of the sulcus in the coordinate system It must be as low as possible. Numerical results show that method 4 always performs better than others (up to $30 \%$ ). Talairach space is quite equivalent, on the surface, to a proportional space (method 2). Remaining differences are due to anatomical intrinsic variations of sulci.

\section{CONCLUSION}

In our atlas of brain sulci, variation of size and shape of the brain is included in the sulcus model. Variability is taken into account by the mean curve of our model. Intrinsic variations are represented by the search area. They are obtained by a registration in the standard Talairach space, followed by a projection onto the surface of the brain. The first step corrects influence of the size of the brain on sulci and the second one the influence of the shape of the surface on sulci. Our model can be used for automatic identification of main cortical sulci on 3D MRI.

\section{REFERENCES}

[1] Ono M., Kubik S., Abernathey C.D. - Atlas of the cerebral sulci. Georg Thieme Verlag, Stuttgart, 1990.

[2] Gee J.C., Reivich M., Bajcsy R. Elastically deforming 3D atlas to match anatomical brain images. J. comp. assist. tomography, vol.17 n², pp 225-236, 1993.

[3] Greitz T., Bohm C., Holte S, Eriksson L. - A computerized brain atlas: construction, anatomical content, and some applications. J.l of computer assisted tomography, vol.15 $\mathrm{n}^{\circ} 1$, pp 26-38, 1991.

[4] Le Goualher G., Barillot C., Le Briquer L., Gee J.C., Bizais Y. - 3D Detection and representation of cortical sulci. CAR'95, Springer Verlag, Berlin, 1995.

[5] Mangin J.F., Regis J., Bloch I., Frouin V., Samson Y., Lopez-Krahe J. - A MRF based random graph modelling the human cortical topography. CVRMed, pp 177-183, Nice, 1995.

[6] Luo S., Evans A.C.- A Method for Matching Human Sulci in 3D-Space. First Int. Conf. on Fonctional Mapping of the Human Brain, Paris, 1995.

[7] Dabringhaus A. and al. - What is a standard brain? Intersubject variability of the shape of the human forebrain. First Int. Conf. on Fonctional Mapping of the Human Brain, Paris, 1995.

[8] Talairach J., Tournoux P.- Co-planar stereotaxic atlas of the human brain. Georg Thieme Verlag, Stuttgart, 1988.

[9] Steinmetz H., Furst G., Freund H.S. - Cerebral cortical localization : application and validation of the proportionnal grid system in MR imaging. J. of Comp. assisted tomography, 1989, vol.13 $\mathrm{n}^{\circ} 1$, pp 10-19.

[10] Royackkers N., Fawal H., Desvignes M., Revenu M., Travère J.M. - Feature extraction for cortical sulci identification. 9th Scandinavian conference on image analysis, pp 1147-1154, Uppsala, 1995. 